\title{
Prevalence of Metabolic Syndrome Among Diabetes Patients in Central Regional Hospital, Cape Coast, Ghana
}

\author{
Heckel Amoabeng Abban 1, *, Precious Barnes², Du-Bois Asante' ${ }^{2}$ Emmanuel Effah-Yeboah ${ }^{2}$, \\ Paul Nsiah $^{3}$, Shadrack Fenuku ${ }^{2}$ \\ ${ }^{1}$ Department of Clinical Nutrition and Dietetics, School of Allied Health Sciences, College of Health and Allied Sciences, University of Cape \\ Coast, Cape Coast, Ghana \\ ${ }^{2}$ Department of Biomedical Sciences, School of Allied Health Sciences, College of Health and Allied Sciences, University of Cape Coast, \\ Cape Coast, Ghana \\ ${ }^{3}$ Department of Chemical Pathology, School of Medical Sciences, College of Health and Allied Sciences, University of Cape Coast, Cape \\ Coast, Ghana
}

\author{
Email address: \\ abbanheckel@gmail.com (H. A. Abban) \\ ${ }^{*}$ Corresponding author
}

\section{To cite this article:}

Heckel Amoabeng Abban, Precious Barnes, Du-Bois Asante, Emmanuel Effah-Yeboah, Paul Nsiah, Shadrack Fenuku. Prevalence of Metabolic Syndrome Among Diabetes Patients in Central Regional Hospital, Cape Coast, Ghana. Journal of Food and Nutrition Sciences. Vol. 5, No. 2, 2017, pp. 34-43. doi: 10.11648/j.jfns.20170502.13

Received: December 30, 2017; Accepted: January 16, 2017; Published: March 18, 2017

\begin{abstract}
Background: Metabolic syndrome (MetS) is a combination of complex group of cardiovascular risk factors, which include central adiposity, high blood pressure, dyslipidaemia and elevated fasting blood glucose. Generally, the prevalence of MetS in diabetes patients is high and the syndrome tends to promote the development of diabetes and other chronic diseases. Diabetes is characterised by high random plasma glucose as well as polyuria, polydipsia and weight loss etc. Aim: This study aims to determine the prevalence of MetS in diabetics' patients using the National Cholesterol Education Programme (NCEP) ATP III criteria, World Health Organisation and International Diabetes Federation definitions in quantifying the syndrome. Method: This cross-sectional study involved 103 diabetes patients in the Cape Coast Metropolis, Central Region. Anthropometric measurements and fasting blood samples for blood sugar and lipids were taken. Blood pressures were recorded from their personal health record files. The NCEP ATP III, WHO and IDF criteria were used to define diabetes patients with the metabolic syndrome. Results: A total of $42(40.8 \%), 31(30.1 \%), 81(78.6 \%)$ were obese, overweight and have high waist circumference (IDF) respectively. Also all the participants had a low high density lipoprotein (HDL) level with 42(95.5\%) having high triglycerides (TG). Significant associations were found for age range of $66-75(\mathrm{OR}=16.00, \mathrm{CI}=1.32-194.62)$, women $(\mathrm{OR}=14.06 ; \mathrm{CI}=2.50-79.05)$ and high blood pressure $(\mathrm{OR}=5.83, \mathrm{CI}=1.22-39.93)$. Prevalence of MetS was 38.60\%, $59.09 \%$ and $75.00 \%$ using WHO, NCEP ATP III and IDF criteria respectively. Conclusion: A high prevalence of MetS was observed among the diabetes patients. The prevalence among the females was higher than that of the males.
\end{abstract}

Keywords: Diabetes, Metabolic Syndrome, Dyslipidaemia, Central Obesity, High Blood Pressure

\section{Introduction}

Metabolic syndrome (MetS) is a combination of complex group of cardiovascular disease risk factors (central adiposity, high blood pressure, dyslipidaemia, and elevated fasting plasma glucose) [1]. Globally, $20-25 \%$ of the adult population has been estimated to have the MetS and is twice as likely to die from and three times as likely to have a heart attack or stroke compared with people without the syndrome [2] and about $70-80 \%$ of the population with diabetes mellitus are diagnosed with MetS [3]. There was a high prevalence rate of over $40 \%$ of the MetS in Urban China, Portugal, United Arab Emirates, Brazil and India, whilst Spain, Hong Kong and Japan recorded prevalence below $10 \%$ [4].

In Africa, the association of MetS with the increased risk 
of developing CVDs was previously thought to be rare but now remains a major public health concern. However, Nigeria records a prevalence of $12.1 \%$ (4). In Ghana, the MetS was found to be prevalent among CVDs patients who were seeking medical attention at Korle-Bu Teaching Hospital (KBTH) [5].

Many chronic conditions have been proven to be associated with MetS. Some of these conditions are CVDs [6], type 2 diabetes [7], cancers [8] and chronic kidney disease (CKD) [9]. The increasing prevalence of obesity and sedentary lifestyles contributes to the prevalence of MetS $[10 ; 11 ; 12]$. MetS appear to promote the development of chronic diseases. MetS is described as a progressive disorder; the several components of MetS tend to worsen over time and collectively contribute to an increased risk for chronic disease [13].

In recent times, there is a dramatic increment in the incidence of diabetes worldwide due to changes in human behaviour and lifestyle. The epidemic is mainly type II diabetes, which is also associated with other conditions such as metabolic syndrome [14]. Diabetes mellitus, which is also a syndrome on its own, is defined as the state of chronic hyperglycaemia. This syndrome is characterised by disordered metabolism resulting in hyperglycaemia. Either absolute insulin deficiency or reduced tissue response, or both can contribute to hyperglycaemia. A person is clinically diagnosed of diabetes mellitus if they show the following conditions: high random plasma glucose in the setting of classical symptoms and signs of diabetes; polyuria, polydipsia, and weight loss [15].

A research in Ghana reveals the association between MetS and sexual dysfunction (SD) in men who were clinically diagnosed with diabetes [16].

This study sought to assess the prevalence of metabolic syndrome and its risk factors among diabetes patients in Cape Coast metropolis, Ghana.

\section{Methodology}

\subsection{Research Design and Setting}

The research was a cross sectional design with diabetic patients who attended clinic at the Central Regional Hospital, Cape Coast, Ghana. These patients are populace of towns and villages within the region.

\subsection{Study Population and Sampling}

In all, 103 diabetes patients consented to participate in the study and convenience sampling approach was used.

\subsection{Data Collection}

Initially, oral consent was sought from the Ethical Committee of the Hospital. Data collection commenced on the $8^{\text {th }}$ March, 2015 to $20^{\text {th }}$ April, 2015.

\subsection{Data Collection Procedure}

Data collection was in four parts: questionnaire interviews, anthropometric measurements, blood pressure measurement and blood lipid biochemistry:

\subsubsection{Questionnaire Interviews}

The interview guide obtained information on sociodemographic data such as gender, age, ethnicity, religion, occupation and education background; risk factors of health history like prevalence of other chronic diseases, duration of diabetes and history of any other chronic diseases were gathered. Moreover, data on dietary intake, lifestyle practices were obtained by means of designed questionnaires. Information on smoking habits and alcohol drinking was also gathered using the questionnaire.

\subsubsection{Anthropometric Measurements}

Anthropometric measurements of waist circumference $(\mathrm{cm})$, weight $(\mathrm{Kg})$ and height $(\mathrm{m})$ were taken. Waist circumference (WC) was measured midway between the suprailiac crest and the inferior angle of the ribs. The measurement was made to the nearest $1 \mathrm{~cm}$ using a non-stretchable fibre-glass measuring tape (Butterfly, China). During the measurement, participants stood in an upright position, with arms relaxed at the side, feet evenly spread apart and body weight evenly distributed in accordance with the WHO expert consultation report on waist circumference and waist-hip ratio. Weight was measured to the nearest $0.1 \mathrm{~kg}$ using a bathroom scale and height was measured using a stadiometer and recorded to the nearest 0.05 $\mathrm{cm}$. BMI categories were selected according to WHO recommendations. According to this standard, individuals with a BMI $\leq 20 \mathrm{~kg} / \mathrm{m}^{2}$, BMI of $20-25 \mathrm{Kg} / \mathrm{m}^{2}$, BMI $25-29.9 \mathrm{Kg} / \mathrm{m}^{2}$ and $\mathrm{BMI} \geq 30 \mathrm{Kg} / \mathrm{m}^{2}$ were classified as been underweight, normal weight, overweight and obese respectively [17].

\subsubsection{Clinical Data}

Participants' clinical parameters of systolic and diastolic blood pressures were recorded from their personal health record files.

\subsubsection{Biochemical Data}

The fasting blood sugar was obtained from the personal record files of each participant. Venous blood specimen were obtained from each subject following a 12-hour overnight fast for measurement of fasting blood sugar level, High Density Lipoprotein cholesterol (HDL-C) and triglyceride (TG). Commercial kits (Medsource Ozone Biomedicals Pvt. Ltd., India) were used to determine HDL-C and triglyceride TG.

The principle for estimation of HDL-C concentration is as follows: When serum was treated with phosphotungstic acid in the presence of magnesium ion, the Low Density Lipoprotain Cholesterol (LDL-C) was precipitated from serum. The HDL fraction remains dissolved in the supernatant, which then acts as a sample and assayed for cholesterol by an enzymatic method as described previously [18].

\subsection{Analysis of Data}

The criteria of the WHO [19], NCEP ATP III [20] and IDF [21] were used to assess the prevalence and risk factors of MetS among the participants. SPSS version 20 was used to 
run logistic regression to find out the association between the risk factors and the MetS. Student $t$ test was used for mean of both metabolic and non-metabolic syndrome group. Moreover, Kappa $(\kappa)$ statistics was used to for finding the agreement between the three definitions. A forward stepwise binary logistic regression model was used to determine the independent predictors of MetS.

\section{Results}

Data on socio-demographic characteristics, anthropometric indicators, biochemical data and lifestyle practices were collected for all 103 diabetes patients except for the lipid profile in which 44 patients were involved.

The socio-demographic characteristics of the study population are depicted in table 1 and this comprises 36 (34.9\%) males and 67 (65.1\%) females. The mean age was $56.24 \pm 9.77$ with a range of 35 to 80 years. The highest frequency age group range of this study was 46-55years, which was36 $(35.0 \%)$ of the total group. Within this range, $10(27.8 \%)$ were males and $26(38.8 \%)$ were females. The lowest frequency age group range was those above 75 years, which was $2(1.9 \%)$ of the total group. A male $(2.8 \%)$ and a female $(1.5 \%)$ were involved.

In terms of formal education, a lot of the participants had attained secondary education. This was followed by those who have had primary education and participants who have had no formal education. About $81(78.7 \%)$ had some education. Out of this, $11(10.7 \%)$ had tertiary education, 48 (46.6\%) had secondary education, $22(21.4 \%)$ had primary education and $22(21.4 \%)$ had no form of formal education. A few of the study population had tertiary school education.

A total of $22(21.4 \%)$ of the study population have whitecollar jobs representing 15 (41.7\%) males with $41.7 \%$ and $7(10.4 \%)$ females. Fifty-seven of the participants who accounted for $55.3 \%$ were engaged in informal jobs such as self-employment among which41 (61.2\%) are females and $16(44.4 \%)$ are males.

Data on religion showed that $86(83.5 \%)$ of the total study population was Christians. This comprises 29 (80.6\%) males and $57(85.1 \%)$ females. Few participants were of the Islamic religion. This constituted $5(4.9 \%)$ of the total participants which included2 (5.6\%) males and 3 (4.5\%) females. Moreover, $12(11.7 \%)$ of the participants belonged to other religions. In terms of ethnicity, majority of the participants were Akans which made up to $76(72.9 \%)$ of the total participants. This was followed by the Northerners, who constitute $7(6.8 \%)$ of the total study population. The Ewes were made up of $2(1.9 \%)$ of the participants whilst a patient $(0.9 \%)$ belonged to the Ga religion. A total of $18(17.5 \%)$ of the participants belonged to other ethnic group.

Table 1. Socio-demographic characteristics of the study population.

\begin{tabular}{|c|c|c|c|c|}
\hline Parameters & Total & Male & Female & P-value \\
\hline & $(\mathrm{N}=103)$ & $(\mathrm{N}=36)$ & $(\mathrm{N}=67)$ & \\
\hline Age & $56.24 \pm 9.77$ & $57.56 \pm 10.09$ & $55.54 \pm 9.60$ & 0.320 \\
\hline $36-45$ & $15(14.6 \%)$ & $5(13.9 \%)$ & $10(14.9 \%)$ & 0.487 \\
\hline $56-65$ & $32(31.1 \%)$ & $15(41.7 \%)$ & $17(25.4 \%)$ & \\
\hline $66-75$ & $18(17.5 \%)$ & $5(13.9 \%)$ & $13(19.4 \%)$ & \\
\hline$>75$ & $2(1.9 \%)$ & $1(2.8 \%)$ & $1(1.5 \%)$ & \\
\hline Primary & $22(21.4 \%)$ & $9(25.0 \%)$ & $13(19.4 \%)$ & \\
\hline Secondary & $48(46.6 \%)$ & $20(55.6 \%)$ & $28(41.8 \%)$ & \\
\hline Tertiary & $11(10.7 \%)$ & $5(13.9 \%)$ & $6(9.0 \%)$ & \\
\hline None & $22(21.4 \%)$ & $2(5.6 \%)$ & $20(29.9 \%)$ & \\
\hline Occupation & & & & 0.001 \\
\hline Formal & $22(21.4 \%)$ & $15(41.7 \%)$ & $7(10.4 \%)$ & \\
\hline Informal & $57(55.3 \%)$ & $16(44.4 \%)$ & $41(61.2 \%)$ & \\
\hline Unemployed & $24(23.3 \%)$ & $5(13.9 \%)$ & $19(28.4 \%)$ & \\
\hline Christian & $86(83.5 \%)$ & $29(80.6 \%)$ & $57(85.1 \%)$ & \\
\hline Islam & $5(4.9 \%)$ & $2(5.6 \%)$ & $3(4.5 \%)$ & \\
\hline Others & $12(11.7 \%)$ & $5(13.9 \%)$ & $7(10.4 \%)$ & \\
\hline Ethnicity & & & & 0.299 \\
\hline Akan & $76(72.9 \%)$ & $26(72.2 \%)$ & $50(74.6 \%)$ & \\
\hline Ewe & $2(1.9 \%)$ & $0(0.0 \%)$ & $2(3.0 \%)$ & \\
\hline $\mathrm{Ga}$ & $1(0.9 \%)$ & $1(2.8 \%)$ & $0(0.0 \%)$ & \\
\hline Northerner & $7(6.8 \%)$ & $4(11.2 \%)$ & $3(4.5 \%)$ & \\
\hline Others & $18(17.5 \%)$ & $6(16.7 \%)$ & $12(17.9 \%)$ & \\
\hline
\end{tabular}

Table 2 shows anthropometric data, clinical and biochemical characteristics. The mean value of Body Mass index (BMI) of the patients was $29.02 \pm 5.73$ and it varied from17.4to 46.7. Most of the participants were found to be obese. This constitutes $42(40.8 \%)$ of the study population of which $34(50.7 \%)$ were females and $8(22.2 \%)$ were males. A total of $31(30.1 \%)$ of the participants were found to be overweight of which 12 (33.3\%) were males and 19 (28.4\%) were females. Those who were having healthy/normal weight were $29(28.2 \%)$ comprising16 (44.4\%) males and 13 
(19.4\%) females. One $(1.0 \%)$ of the total study population was found to be underweight.

According to the IDF criterion, $22(21.4 \%)$ of the study population had normal WC of which $18(50.0 \%)$ were males and $4(6.0 \%)$ were females. Nonetheless, majority of the study participants had a higher WC. Eighty - one which accounted for $78.6 \%$ of the remaining participants had a high WC comprising $18(50.0 \%)$ males and $63(94.0 \%)$ females. With the NCEP ATP III definition, $68(66.0 \%)$ had a high WC of which $9(25.0 \%)$ were males and 59 (88.1\%) were females. Consequently, minority fell below the cut-off points. The remaining participants who constituted 35 (34.0\%) had normal WC of which 27 (75.0\%) were males and 8 (11.9\%) were females. The mean WC was $99.60 \pm 16.35$.

According to IDF/NCEP ATP III criteria, 43 (41.8\%) of the participants had high blood pressure recording that had values $\geq 130 / 85 \mathrm{mmHg}$ whilst $60(58.2 \%)$ had normal blood pressure that had values $<130 / 85 \mathrm{mmHg}$. Also based on WHO definition, $73(70.9 \%)$ of the study population had their blood pressure to be normal whilst 30 (29.1\%) of the participants had high blood pressure. The mean systolic blood pressure $(\mathrm{mmHg})$ was $128.86 \pm 22.37$ and that for diastolic blood pressure was $74.23 \pm 10.76$.

Biochemical assays showed that the mean HDL cholesterol $(\mathrm{mmol} / \mathrm{L})$ was $0.11 \pm 0.16$ and the mean of triglyceride $(\mathrm{mmol} / \mathrm{L})$ was $1.09 \pm 3.52$. The mean fasting blood sugar (FBS) was $9.32 \pm 6.75 \mathrm{mmol} / \mathrm{L}$. All the participants 44 (100.0\%) had low HDL-C with42 (95.5\%) also having high triglycerides and $2(4.5 \%)$ having low triglycerides.

Table 2. Anthropometric, clinical and biochemical characteristics of the study population.

\begin{tabular}{|c|c|c|c|c|}
\hline & Total & $\mathbf{M}$ & $\mathbf{F}$ & P-value \\
\hline Parameters & $(\mathrm{N}=103)$ & $(\mathrm{N}=36)$ & $(\mathrm{N}=67)$ & \\
\hline BMI & & & & 0.014 \\
\hline Underweight & $1(1.0 \%)$ & $0(0.0 \%)$ & $1(1.5 \%)$ & \\
\hline Overweight & $31(30.1 \%)$ & $12(33.3 \%)$ & $19(28.4 \%)$ & \\
\hline Obese & $42(40.8 \%)$ & $8(22.2 \%)$ & $34(50.7 \%)$ & \\
\hline $\mathrm{BMI}\left(\mathrm{Kg} / \mathrm{m}^{2}\right)$ & $29.02 \pm 5.73$ & $26.61 \pm 4.14$ & $30.31 \pm 6.07$ & 0.001 \\
\hline$\geq 130 / 85$ & $43(41.8 \%)$ & $13(36.1 \%)$ & $30(44.8 \%)$ & \\
\hline$<130 / 85$ & $60(58.2 \%)$ & $23(62.5 \%)$ & $37(55.2 \%)$ & \\
\hline $\mathrm{BP}(\mathrm{WHO})$ & & & & 0.994 \\
\hline$\geq 140 / 90$ & $30(29.1 \%)$ & $11(30.6 \%)$ & $19(28.4 \%)$ & \\
\hline$<140 / 90$ & $73(70.9 \%)$ & $25(69.4 \%)$ & $48(71.6 \%)$ & \\
\hline $\mathrm{SBP}(\mathrm{mm} / \mathrm{Hg})$ & $128.86 \pm 22.37$ & $127.33 \pm 22.39$ & $129.69 \pm 22.49$ & 0.613 \\
\hline $\mathrm{DBP}(\mathrm{mm} / \mathrm{Hg})$ & $74.23 \pm 10.76$ & $74.78 \pm 8.45$ & $73.94 \pm 11.87$ & 0.708 \\
\hline WC (IDF) & & & & 0.000 \\
\hline High & $81(78.6 \%)$ & $18(50.0 \%)$ & $63(94.0 \%)$ & \\
\hline WC (NCEP) & & & & 0.000 \\
\hline Low & $35(34.0 \%)$ & $27(75.0 \%)$ & $8(11.9 \%)$ & \\
\hline High & $68(66.0 \%)$ & $9(25.0 \%)$ & $59(88.1 \%)$ & \\
\hline $\mathrm{WC}(\mathrm{cm})$ & $99.60 \pm 16.35$ & $92.74 \pm 11.53$ & $103.28 \pm 17.42$ & 0.002 \\
\hline \multicolumn{5}{|l|}{ HDL } \\
\hline Low & $44(100.0 \%)$ & $17(100.0 \%)$ & $27(100.0 \%)$ & \\
\hline HDL (mmo/l/) & $0.11 \pm 0.16$ & $0.10 \pm 0.11$ & $0.12 \pm 0.18$ & 0.613 \\
\hline TG & & & & 0.512 \\
\hline$\geq 150$ & $42(95.5 \%)$ & $15(88.2 \%)$ & $27(100.0 \%)$ & \\
\hline$<150$ & $2(4.5 \%)$ & $2(11.8 \%)$ & $0(0.0 \%)$ & \\
\hline $\mathrm{TG}(\mathrm{mmo} / \mathrm{l} /)$ & $1.09 \pm 3.52$ & $1.11 \pm 0.49$ & $1.09 \pm 0.23$ & 0.860 \\
\hline FBS $(\mathrm{mmo} / \mathrm{l} /)$ & $9.32 \pm 6.75$ & $9.45 \pm 6.22$ & $9.26 \pm 7.06$ & 0.891 \\
\hline
\end{tabular}

$\mathrm{BMI}=$ Body mass index, $\mathrm{BP}=\mathrm{Blood}$ pressure, $\mathrm{SBP}=$ Systolic blood pressure, $\mathrm{DBP}=$ Diastolic blood pressure, WC$=$ Waist circumference, $\mathrm{FBS}=\mathrm{Fasting}$ blood sugar

Table 3 depicts the physical activities of the participants. Brisk walking was the main physical activity undertaken by most of the study population. The total number of participants who engaged in this activity was $47(45.5 \%)$ of the study population representing 34 (50.7\%) females and 13 (36.1\%) males. Other physical activities engaged by the participants were jogging, 5 (4.9\%); swimming, 1 (0.9\%); weeding, $2(1.9 \%)$ and jumping, $1(0.9 \%)$ for an average duration of 80 minutes, 30 minutes, 25 minutes and 30 minutes respectively. Also, some of the participants were involved in other physical activities such as skipping, 3 (2.9\%) and stretching, $1(0.9 \%)$ for an average duration of 30minutes each. A total of $17(16.5 \%)$ of the study population were not involved in any regular physical activity of which $3(8.3 \%)$ were males and $14(20.9 \%)$ were females.

In terms of lifestyle as depicted in table 3, 98 (95.1\%) have no history of smoking cigarette with only $5(4.9 \%)$ of the study population having been involved in the smoking of cigarette $(\mathrm{p}=0.030)$. Some of the participants frequently take in alcoholic beverages representing $34(33.0 \%)$ of the total population. Out of this, $16(44.4 \%)$ were males and 18 $(26.9 \%)$ were females. It was also observed from the table 
that relatively fewer participants occasionally take in alcohol representing $14(13.6 \%)$.

Table 3. Lifestyle practices of the study population.

\begin{tabular}{llll}
\hline & Total & Male & Female \\
\hline & $(\mathrm{N}=103)$ & $(\mathrm{N}=36)$ & $(\mathrm{N}=67)$ \\
Physical Activity & & & \\
Walking & $47(45.6 \%)$ & $13(36.1 \%)$ & $34(50.7 \%)$ \\
Duration (mins) & 50 & 55 & 45 \\
Cycling & $2(1.9 \%)$ & $2(5.6 \%)$ & $0(0.0 \%)$ \\
Duration (mins) & 120 & 120 & - \\
Football & $1(0.9 \%)$ & $1(2.8 \%)$ & $0(0.0 \%)$ \\
Duration (mins) & 60 & 60 & - \\
Jogging & $5(4.9 \%)$ & $5(13.9 \%)$ & $0(0.0 \%)$ \\
Duration (mins) & 80 & 80 & - \\
Swimming & $1(0.9 \%)$ & $1(2.8 \%)$ & $0(0.0 \%)$ \\
Duration (mins) & 30 & 30 & - \\
Weeding & $2(1.9 \%)$ & $2(5.6 \%)$ & $0(0.0 \%)$ \\
Duration (mins) & 25 & 25 & - \\
Jumping & $1(0.9 \%)$ & $0(0.0 \%)$ & $1(1.5 \%)$ \\
Duration (mins) & 30 & - & 30 \\
Skipping & $3(2.9 \%)$ & $0(0.0 \%)$ & $3(4.5 \%)$ \\
Duration (mins) & 30 & - & 30 \\
Stretching & $1(0.9 \%)$ & $0(0.0 \%)$ & $1(1.5 \%)$ \\
Duration (mins) & 30 & - & 30 \\
None & $17(16.5 \%)$ & $3(8.3 \%)$ & $14(20.9 \%)$ \\
Smoking & $5(4.9 \%)$ & $4(11.1 \%)$ & $1(1.5 \%)$ \\
Yes & $98(95.1 \%)$ & $32(88.9 \%)$ & $66(98.5 \%)$ \\
No & $14(13.6 \%)$ & $9(25.0 \%)$ & $5(7.5 \%)$ \\
Alcohol intake & $34(33.0 \%)$ & $16(44.4 \%)$ & $18(26.9 \%)$ \\
Occasionally & $55(53.4 \%)$ & $11(30.6 \%)$ & $44(65.7 \%)$ \\
Frequently & & & \\
No & $50 \%)$ & \\
\hline & & & \\
\hline
\end{tabular}

mins $=$ minutes

Table 4 represents data on management of diabetes and dietary intake of patients. Participants provided information on how their diabetic condition was managed. From the data gathered, a total of $85(82.5 \%)$ were on diet therapy and medication in the form of tablets to manage their condition of which $57(85.1 \%)$ were females and $28(77.8 \%)$ were males. A total of13 $(12.6 \%)$ were on diet, tablets and insulin therapy. The least number of $2(2.9 \%)$ used diet and insulin to manage their condition. Another group provided no specific way of managing their diabetic condition. Information on the duration of therapy (DOT) was gathered. One participant (1.0\%) had been on therapy for less than a year. It was also observed that a total of 52(50.5\%) of the participants have received therapy for year range of $1-5 y$ years for which $18(50.0 \%)$ were males and $34(50.7 \%)$ were females. From the range of 6-10years, another group of $21(20.4 \%)$ has been on therapy. This is followed by $27(26.2 \%)$ of the study population who had received therapy for more than 10years.

In terms of dietary intake, most of the participants had carbohydrate as the main nutrient in their diet with some people adding fruits and vegetables. From table 4, it was observed that $48(46.6 \%)$ of the study population occasionally took in fruits and vegetables as part of their diets. Out of this, $19(52.8 \%)$ were males and 29 (43.3\%) were females. However, $31(30.1 \%)$ regularly added fruits and vegetables to their diet of which $31(30.6 \%)$ were males and $20(29.9 \%)$ were females. A total number of 24 (23.3\%) rarely added fruits and vegetables as part of their diet.

Table 4. Condition management and dietary intake characteristics of the study population.

\begin{tabular}{lllll}
\hline Parameters & Total & Male & Female & $P$-value \\
\hline & $(\mathrm{N}=103)$ & $(\mathrm{N}=36)$ & $(\mathrm{N}=67)$ & \\
Therapy & & & & 0.110 \\
$\mathrm{D} / \mathrm{I}$ & $3(2.9)$ & $3(8.3)$ & $0(0.0)$ & \\
$\mathrm{D} / \mathrm{T}$ & $85(82.5)$ & $28(77.8)$ & $57(85.1)$ & \\
$\mathrm{D} / \mathrm{T} / \mathrm{I}$ & $13(12.6)$ & $4(11.1)$ & $9(13.4)$ & \\
None & $2(1.9)$ & $1(2.8)$ & $1(1.5)$ & \\
DOT $(\mathrm{yr})$ & & & & 0.780 \\
$<1$ & $1(1.0)$ & $0(0.0)$ & $1(1.5)$ & \\
$1-5$ & $52(50.5)$ & $18(50.0)$ & $34(50.7)$ & \\
$6-10$ & $21(20.4)$ & $8(22.2)$ & $13(19.4)$ & \\
$>10$ & $27(26.2)$ & $10(27.8)$ & $17(25.4)$ & \\
None & $2(1.9)$ & $0(0.0)$ & $2(3.0)$ & \\
Fruits/Vegetables & & & & 0.472 \\
Occasionally & $48(46.6)$ & $19(52.8)$ & $29(43.3)$ & \\
Regularly & $31(30.1)$ & $11(30.6)$ & $20(29.9)$ & \\
None & $24(23.3)$ & $6(16.7)$ & $18(26.9)$ & \\
\hline
\end{tabular}

$\mathrm{D} / \mathrm{I}=$ Diet and insulin, $\mathrm{D} / \mathrm{T}=$ Diet and tablets, $\mathrm{D} / \mathrm{T} / \mathrm{I}=$ Diet, tablets and insulin, DOT=Duration of therapy

Tables 5 and 6 show the logistic regression of factors that are associated with MetS according to the various criteria used. This was performed in order to determine the independent predictors of the prevalence of MetS. As shown in the table, 7 predictor variables socio-demographic, lifestyle, clinical and anthropometric characteristics were tested using the WHO, IDF and NCEP ATP III criteria. The presence or absence of MetS was the dependent variable. The age ranges of 46-55 and 56-65 showed that there were strong associations with MetS but this was not statistically significant according to the WHO criterion. The strongest association with MetS and statistically significant $(\mathrm{P}<0.05)$ age range was 66-75years $(\mathrm{OR}=16.00, \mathrm{CI}=1.32-194.62)$. However, the definition of IDF did not show a strong association between the age range of 56-75years and MetS. According to the NCEP ATP III definition (in table 6), the age ranges of $46-55,66-75$ and $\geq 75$ have strong association with MetS but statistically not significant.

By using the IDF definition, there was 14 higher risk among women of developing MetS than men $(\mathrm{OR}=14.06$; $\mathrm{CI}=2.50$ 79.05). This result was significant $(p=0.003)$. Formal occupation was strongly associated with MetS with a significant result $(\mathrm{p}=0.000)$ according to the WHO criterion, $(\mathrm{OR}=7.90 ; \quad \mathrm{CI}=1.97-8.19)$. Although not statistically significant, alcohol consumption was not a risk factor for developing MetS according to all the criteria. Smoking cigarette has a strong association with MetS as the IDF definition showed. There was a 5 times higher risk for diabetes patients who have high blood pressure to develop MetS $(\mathrm{OR}=5.83 ; \mathrm{CI}=1.22-39.93)$. This result, as provided by the NCEP ATP III criterion, was statistically significant $(\mathrm{p}=0.018)$.

In terms of body BMI, there were strong associations with MetS for underweight, overweight and the obese according to the WHO criterion but these results were not statistically significant. The IDF definition also provides a strong 
association of underweight with MetS but the criterion does not include overweight and obesity. The NCEP ATP III criterion provides no strong association of underweight, overweight and obesity with the syndrome and the results were not significant $(p=0.997)(O R=0.00 ; C I=0.00)$.

Table 5. Logistic regression of factors associated with metabolic syndrome according to the WHO and IDF criteria.

\begin{tabular}{|c|c|c|c|c|}
\hline & WHO & & IDF & \\
\hline Parameters & OR $(95 \% \mathrm{CI})$ & P-value & OR $(95 \% \mathrm{CI})$ & P-value \\
\hline \multicolumn{5}{|l|}{ Age (years) } \\
\hline $36-45$ & Reference & - & Reference & - \\
\hline $46-55$ & $9.33(0.89-97.62)$ & 0.062 & $0.95(0.13-7.28)$ & 0.962 \\
\hline $56-65$ & $1.60(0.122-20.99)$ & 0.128 & $0.57(0.08-6.12)$ & 0.579 \\
\hline $66-75$ & $16.00(1.32-194.62)$ & 0.030 & $1(0.10-9.2)$ & 1 \\
\hline$\geq 75$ & $9.28(9.28-9.28)$ & - & $7.75(7.75-7.75)$ & - \\
\hline Male & Reference & - & Reference & - \\
\hline Female & $1.26(0.35-4.42)$ & 0.718 & $14.06(2.50-79.05)$ & 0.003 \\
\hline \multicolumn{5}{|l|}{ Occupation } \\
\hline None & Reference & - & Reference & - \\
\hline Formal & $7.90(1.95-8.19)$ & 0.000 & $4.50(0.19-106.82)$ & 0.352 \\
\hline Informal & $3.62(3.62-3.62)$ & - & $2.87(0.16-51.53)$ & 0.473 \\
\hline \multicolumn{5}{|l|}{ Alcohol intake } \\
\hline \multicolumn{5}{|l|}{ Smoking } \\
\hline Yes & $0.00(0.00)$ & - & $9.15(9.15-9.15)$ & - \\
\hline No & Reference & - & Reference & - \\
\hline \multicolumn{5}{|l|}{$\mathrm{BP}$} \\
\hline High & $4.02(0.95-16.91)$ & 0.057 & $1.96(0.09-4.58)$ & 0.376 \\
\hline Low & Reference & - & Reference & - \\
\hline \multicolumn{5}{|l|}{ BMI } \\
\hline Underweight & $5.53(0.00)$ & 0.997 & 8.77 (8.77-8.77) & - \\
\hline Normal & Reference & - & Reference & - \\
\hline Overweight & $4.17(0.00)$ & 0.998 & $0.22(0.01-7.13)$ & 0.401 \\
\hline Obese & $1.68(0.00)$ & 0.997 & $0.03(0.03-19.38)$ & 0.830 \\
\hline
\end{tabular}

Table 6. Logistic regression of factors associated with metabolic syndrome according to the NCEP ATP III criteria.

\begin{tabular}{|c|c|c|}
\hline & NCEP ATP III & \\
\hline Parameters & OR $(95 \% C I)$ & P-value \\
\hline \multicolumn{3}{|l|}{ Age (years) } \\
\hline $36-45$ & Reference & - \\
\hline $46-55$ & $2.81(0.48-16.43)$ & 0.251 \\
\hline $56-65$ & $0.89(0.15-5.11)$ & 0.899 \\
\hline $66-75$ & $4.37(0.56-33.94)$ & 0.158 \\
\hline$\geq 75$ & $2.17(2.17-2.17)$ & \\
\hline \multicolumn{3}{|l|}{ Gender } \\
\hline Male & Reference & - \\
\hline Female & $2.25(0.64-7.80)$ & 0.201 \\
\hline \multicolumn{3}{|l|}{ Occupation } \\
\hline None & Reference & - \\
\hline Formal & $2.66(0.12-57.62)$ & 0.532 \\
\hline Informal & $1.21(0.06-21.21)$ & 0.894 \\
\hline \multicolumn{3}{|l|}{ Drinking } \\
\hline Yes & $0.85(0.25-2.85)$ & 0.802 \\
\hline No & Reference & - \\
\hline \multicolumn{3}{|l|}{ Smoking } \\
\hline Yes & $0.00(0.00)$ & - \\
\hline No & Reference & - \\
\hline \multicolumn{3}{|l|}{ BP } \\
\hline High & $5.83(1.22-39.93)$ & 0.018 \\
\hline Low & Reference & - \\
\hline \multicolumn{3}{|l|}{ BMI } \\
\hline Underweight & $0.00(0.00)$ & 0.997 \\
\hline Normal & Reference & - \\
\hline Overweight & $0.00(0.00)$ & 0.997 \\
\hline Obese & $0.00(0.00)$ & 0.997 \\
\hline
\end{tabular}

$\mathrm{OR}=$ Odd ratio, $\mathrm{CI}=$ Confidence interval 
Also, the prevalence of MetS was 17 (38.60\%), 26 $(59.09 \%)$ and $33(75.00 \%)$ using WHO, NCEP ATP III and IDF criteria respectively. Figure 1 shows the prevalence of MetS according to WHO criterion. Figures 2 and 3 indicate the prevalence of MetS according to IDF and NCEP ATP III criteria respectively. Generally, the prevalence among women was higher than that of the men. In terms of age $(p=0.487)$, occupation $(p=0.001)$, educational status $(p=0.04)$, body mass index $(p=0.014)$ together with systolic and diastolic blood pressure $(\mathrm{p}=0.846)$, there was a significant difference between males and females.

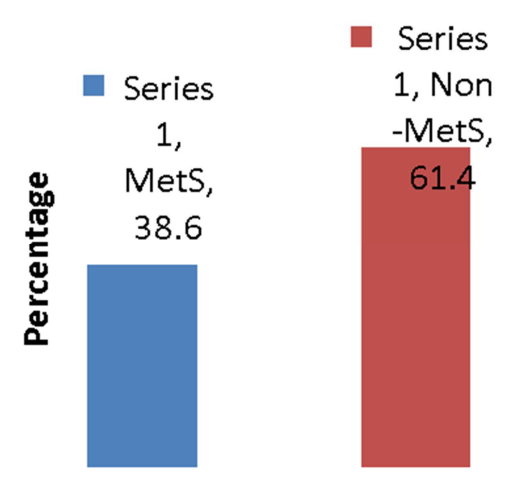

Figure 1. Prevalence of MetS according to WHO criterion was $38.6 \%$.

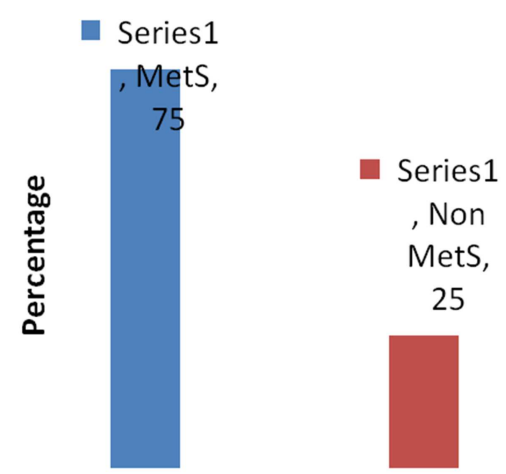

Figure 2. Prevalence of MetS according to the IDF criterion was 75\%.

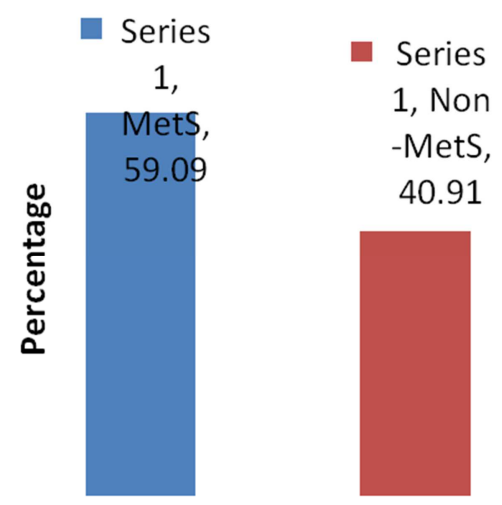

Figure 3. Prevalence of MetS according to NCEP criterion was $59.09 \%$.

Most of the subjects who were classified as having the MetS according to the NCEP ATP III definition also met the criterion of IDF. Nonetheless, 7 (15.91\%) of the subjects diagnosed with MetS according to IDF definition were not found to have the syndrome according to the NCEP ATP III criterion. This actually showed good agreement between the criteria provided by both NCEP ATP III and IDF. There is also a good agreement between the criteria provided by both WHO and NCEP ATP III in that most of the subjects with the MetS according to the WHO criterion also met the definition of NCEP ATP III. However, $20.49 \%$ of the subjects with the MetS according to the NCEP ATP III criterion were not found to have the condition by using the WHO definition.

On the other hand, the prevalence of MetS among the subjects was not in good agreement according to the definitions provided by the IDF and WHO. About 16 (36.40\%) of the subjects with MetS according to the WHO criterion were positive for IDF definition.

\section{Discussion}

This study reports a high prevalence of MetS among diabetes patients in the Cape Coast Metropolis. The prevalence of MetS is $33(75.0 \%), 26(59.1 \%)$ and 17 (38.6\%) according to the IDF, NCEP ATP III and WHO criteria respectively. This finding is comparable with other studies performed among diabetes patients in Cameroon where the prevalence of MetS was $71.7 \%$ and $60.4 \%$ according to the IDF and NCEP ATP III criteria respectively [22]. It is estimated that majority of diabetes patients have MetS [23]. To buttress this point, a study of heart disease conducted by [24] among NHANES III participants reported that $37.4 \%$ in the group were found have MetS without diabetes and $50.3 \%$ in the group were found to have both MetS and diabetes. The study by [25] found out that the prevalence of MetS among 456 diabetes patients in Kumasi to be $55.9 \%$ based on the NCEP ATP III criterion. This study attributed the prevalence to low HDL-C concentration (47.4\%) and hypertension (46.9\%). Another study also records a prevalence of $77.2 \%$ among type 2 diabetes patients in Mumbai [26]. Contrary to this, a lower prevalence of $25.2 \%$ of MetS has been found among diabetes patients in Nigeria based on the WHO criterion [27].

The difference in the prevalence could be accounted for by the different cut-off points in terms of abdominal obesity and blood pressure. Also, the other studies are more current than the study among Nigerians and the prevalence of diet-related health conditions tend to increases with time due to nutritional transition, and globalisation, etc. Non-healthy eating habits may be responsible for high prevalence recorded. It was observed that a number of participant occasionally added fruits and vegetables to their meals. Dietary fibre of fruits and vegetables tend to reduce cholesterol levels in the blood. The IDF criterion requires that the cut-off points for the abdominal obesity be reduced. Also the blood pressure cut-off point was reduced for both IDF and NCEP ATP III. These factors contributed to the high prevalence of MetS recorded by the IDF and NCEP ATP III criteria. 
In terms of lipid profile, all the participants had a low HDL-C concentration but $2(4.5 \%)$ of the total study population had a low triglyceride concentration. The increase in physical activity results in an increase in HDL-C and decrease in triglyceride levels [28]. Therefore, the low HDL$\mathrm{C}$ and high triglyceride concentrations recorded may be accounted for by low level of physical activity among the participants. Consequently, $42(95.5 \%)$ of the study population had high level of triglyceride concentration. Low triglyceride concentration is protective against the development of MetS.

It is noted in this study that a good agreement of Kappa value exists between the definitions of both the NCEP ATP III and IDF $(\kappa=0.450)$. This is evident in the highest value provided. Another good agreement of Kappa value is observed between the WHO and NCEP ATP III criteria ( $\mathrm{K}$ $=0.433$ ). This finding is similar in study conducted by [29] in India. But the definitions of WHO and IDF provide the least agreement $(\kappa=0.102)$.

Another important finding of this study was that the prevalence of the MetS found in women was relatively higher than in men. This finding agrees with several studies conducted among type 2 diabetes patients in Sub-Saharan Africa [30, 22] and other developing countries [31, 32]. The reason behind the higher prevalence in females could be the lower cut-off point for the waist circumference and the higher cut-off point for the HDL cholesterol. Relatively, many women rarely add fruits and vegetables to their dietary intake. Also, obesity as a major risk for diet-related chronic diseases such as type 2 diabetes, hypertension and stroke may be responsible for high prevalence [33]. It is therefore important to acknowledge that women should become a focus for high risk target screening, and attempts should be made to normalize each component of the MetS so as to minimize the risk of cardiovascular diseases [31].

It was also observed that a predisposing factor of the MetS was age, that is, as diabetes patient ages the severity of MetS worsens or the risk of developing MetS increases. It was observed that most of the participants were old and this could have contributed to the high prevalence of MetS recorded. This finding is comparable to other findings in sub-Saharan Africa by [34]. Other studies also support the fact that age is a risk factor of MetS [35, 36].

Moreover, it is found in literature that physical activity is protective against the development of MetS through improvements in plasma lipid concentrations, especially through increasing HDL-C [28], decrease in triglyceride level [37] or both [38]. A study by [39] reveals that physical activity increases HDL-C and reduces fasting blood glucose level. Physical activity improves glucose tolerance, reduces blood pressure [40], insulin sensitivity [41] and lowered risk of type 2 diabetes [42]. In this study, it was noted that 47 $(45.6 \%)$ of the study population engaged in brisk walking in an average duration of 50minutes as their main physical activity. Even though this is a form of physical activity, participants could also indulge themselves in other kind of exercise in order to obtain most of the benefits derived from physical activities. It could also be predicted that this physical activity was protective against the condition for the non-metabolic syndrome patients.

Several studies have identified high prevalence of MetS among sedentary population [43,44] and low prevalence of MetS in active population [45]. Other studies have shown that the sedentary people have broader central adiposity (waist circumference) [46] and higher mean blood pressure [47]. This study have identified that most of the participants were obese, $42(40.8 \%)$ corresponding to the higher number of participants who had broader waist circumference. This obese category was dominated by the females 34 (50.7\%) as compared to $8(22.2 \%)$ of the males. The reason behind the broader central adiposity recorded among the sedentary individuals could be accounted for by their low physical activity leading to the accumulation of fat. In terms of the central adiposity, the females had relatively broader waist circumference than the males by the IDF and NCEP ATP III criteria used. Generally, few participants had their waist circumference below the cut-off points for both criteria.

Predictors of metabolic syndrome

High blood pressure was found to be a risk factor in this study. There is 5 times higher risk for diabetes patients with high blood pressure to develop MetS $(\mathrm{OR}=5.83$; $\mathrm{CI}=1.22$ 39.93). This result, as provided by the NCEP ATP III criterion, was statistically significant $(p=0.018)$. This can be due to the fact that high blood pressure is normally associated with hyperlipidaemia hence central obesity which is the main culprit of MetS. Age was also found to be a predictor of MetS and this can be as a result of low physical activity as one ages which in turn leads to accumulation of fat and also weakening of blood vessels as one ages which leads to high blood pressure.

Formal occupation or white collar jobs was found to be a predictor. This boils down to the sedentary lifestyle and sometimes stress associated with most of these jobs.

On the gender front, women were found to be at an increased risk of developing MetS compared to their male counterpart and this also can be due to the fact that most women are less physically active.

\section{Conclusion}

The main determinants of MetS were age, gender (female) and occupation (white collar jobs). Prevalence of MetS was high and this calls for the need for health professional to assess their patients on regular basis and also educate their patients on healthy living.

\section{Acknowledgement}

The authors acknowledge the support of the Head of department for Biomedical Sciences and the staff and diabetes patients of Central Regional Teaching Hospital, Cape Coast, for providing us with the facility and the necessary data. Authors are also grateful to NoRHS (Network of Researchers in Health Sciences), UCC, for their immense support and 
contribution to the success of this work.

\section{References}

[1] R. H. Eckel, S. M. Grundy, and P. Z. Zimmet, "The metabolic syndrome" Lancet, vol. 365, no. 9468, pp.1415-1428, 2005.

[2] M. P. Stern, K. Williams, C. González-Villalpando, K. J. Hunt, and S. M. Haffner, "Does the metabolic syndrome improve identification of individuals at risk of type 2 diabetes and/or cardiovascular disease?" Diabetes Care, vol. 27, no. 11, pp. 2676-2681, 2004.

[3] G. Marchesini, G. Forlani, F. Cerrelli, R. Manini, S. Natale, L. Baraldi, G. Ermini, G. Savaroni, D. Zocchi, and N. Melchionda, "WHO and ATPIII proposals for the definition of the metabolic syndrome in patients with type 2 diabetes", Diabetic Medicine, vol. 21, no.4, pp. 383-387, 2004.

[4] M. Gyakobo, A. G. B. Amoah, D. A. Martey-Marbell, and R. C. Snow, Prevalence of the metabolic syndrome in a rural population in Ghana" BMC Endocrine Disorders, vol. 12 p.25, 2012.

[5] J. Akpalu, A. Akpalu, and F. Offei, "The metabolic syndrome among patients with cardiovascular disease in Accra, Ghana", Ghana Medical Journal, vol. 45, no.4, pp.161-166, 2011.

[6] S. Mottillo, K. B. Filion, J. Genest, L. Joseph, L. Pilote, P. Poirier, S. Rinfret, E. L. Schiffrin, and M. J. Einsenberg, "The metabolic syndrome and cardiovascular risk a systematic review and meta-analysis", Journal of American College of Cardiology, vol. 56, no.14, pp.1113-1132, 2010.

[7] E. S. Ford, C. Li, and N. Sattar, "Metabolic syndrome and incident diabetes: current state of the evidence," Diabetes Care, vol. 31, no. 9, pp. 1898-1904, 2008.

[8] K. Esposito, P. Chiodini, A. Colao, A. Lenzi, and D. Giugliano, "Metabolic syndrome and risk of cancer: a systematic review and meta-analysis", Diabetes Care vol. 35, no. 11 , pp.2402-2411, 2012.

[9] J. Chen, P. Muntner, L. L. Hamm, D. W. Jones, V. Batuman, V. Fonseca, P. K. Whelton, and J He, "The metabolic syndrome and chronic kidney disease in US adults detected by the National Diabetes Data group or the Carpenter and Coustan plasma glucose, " Annals of Internal Medicine, vol. 140, no. 3, pp. 167-174, 2004.

[10] E. Bonora, G. Targher, G. Formentini, F. Calcaterra, S. Lombardi, F. Marini, L. Zenari, F. Saggiani, M. Poli, S. Perbellini, A. Raffaelli, L. Gemma, L. Santi, R. C. Bonadonna and M. Muggeo, "The metabolic syndrome is an independent predictor of cardiovascular disease in type 2 diabetic subjects Prospective data from the Verona Diabetes Complications Study", Journal of Diabetic Medicine, vol. 21, no. 1, pp. 5258, 2004.

[11] A. J. Cameron, J. E. Shaw, and P. Z. Zimmet, "The metabolic syndrome: prevalence in world-wide populations", Journal of Endocrinology Metabolism Clinics of North America, vol. 33, no. 2, pp. 351-375, 2004.

[12] D. J. Magliano, A. Cameron, J. E. Shaw, and P. Z. Zimmet, "Epidemiology of metabolic syndrome. In: Ekoé JM, Rewers M, Williams R, Zimmet P, editors. Epidemiology of diabetes mellitus. 2nd ed. Chichester (UK): Wiley-Blackwell 31-49, 2008.
[13] S. M. Grundy, "Metabolic syndrome: a multiplex cardiovascular risk factor", Journal of Clinical Endocrinology and Metabolism vol. 92, no. 2, pp. 399-404, 2007.

[14] M. P. Stern, K. Williams, C. González-Villalpando, K. J. Hunt, and S. M. Haffner, "Does the metabolic syndrome improve identification of individuals at risk of type 2 diabetes and/or cardiovascular disease?", Diabetes Care, vol. 27, no. 11, pp. 2676-2681, 2004

[15] K. Lundback, "Intravenous glucose tolerance as a tool in definition and diagnosis of diabetes mellitus", $3 v$ Med $J$ vol.1, no. 5291, pp. 1507-1513, 1962.

[16] N. Amidu, W. K, B. A. Owiredu, H. Alidu, C. Sarpong, and C. K. Gyasi Sarpong, "Association between metabolic syndrome and sexual dysfunction among men with clinically diagnosed diabete". Journal of Diabetology and Metabolic Syndrome, vol. 5, p. 42, 2013.

[17] WHO, "Physical status: the use and interpretation of anthropometry. Report of a WHO Expert Committee. WHO Technical Report Series 854. Geneva: World Health Organization, 1995.

[18] N. W. Tietz, "Fundamentals of Clinical Chemistry," Saunders Inc., Philadelphia, PA, p. 329, 1970.

[19] K. G. Alberti, P. Zimmet, and J. Shaw, "The metabolic syndrome - a new world wide definition" Lancet, vol. 366, no. 9491, pp.1059-1062, 2005.

[20] Executive Summary of the Third Report of The National Cholesterol Education Program (NCEP), "Expert Panel on Detection, Evaluation, And Treatment of High Blood Cholesterol In Adults (Adult Treatment Panel III)", Journal of American Medical Association, vol. 285 pp. 2486-2497, 2001.

[21] K. G. Alberti, P. Zimmet, and J. Shaw, "Metabolic syndrome a new world-wide definition. A Consensus Statement from the International Diabetes Federation", 2006.

[22] A. P. Kengne, S. N. Limen, E. Sobngwi, C. F. T. Djouogo, and C. Nouedoui, Metabolic syndrome in type 2 diabetes: comparative prevalence according to two sets of diagnostic criteria in sub-Saharan African", Diabetology and Metabolic Syndrome, vol. 4, no. 1, pp. 22-22, 2012.

[23] S. Isezuo, and E. Ezunu, "Demographic and clinical correlates of metabolic syndrome in Native African type-2 diabetic patients", Journal of National Medical Association, vol. 97, no. 5, pp. 557-563, 2005.

[24] C. M. Alexander, P. B. Landsman, S. M. Teutsch, and S. M. Haffner, "NCEP-Defined Metabolic Syndrome, Diabetes, and Prevalence of Coronary Heart Disease Among NHANES III Participants Age 50 Years and Older", Diabetes, vol. 52, no.5 pp. 1210-1214, 2003.

[25] F. V. K. Titty, W. K. B. A. Owiredu, and M. T. Agyei Frempong, "Prevalence of MetS and its individual components among Diabetic patients in Ghana", Journal of Biological Science, vol. 8, pp. 1057-1061, 2008.

[26] S. P. Surana, D. B. Shah, K. Gala, S. Susheja, S. S. Hoskote, N. Gill, S. R. Joshi, and V. Panikar, 2008, Prevalence of Metabolic Syndrome in an Urban Indian Diabetic Population using The NCEP ATP III Guidelines, Journal of Assocation of Physicians in India, 56 865-868. 
[27] C. O. Alebiosu, and B. O. Odusan, "Metabolic syndrome in subjects with type-2 diabetes mellitus". Journal of National Medical Association, vol. 96, no. 6, pp. 817-821, 2004.

[28] A. S. Leon, and O. A. Sanchez, "Response of blood lipids to exercise training alone or combined with dietary intervention", Medicine and Science in Sports and Exercises vol.33, no. 6, pp. S502-15; discussion S528-9., 2001.

[29] A. K. Ahmed, T. E. Yasmeen, T. S. Awan, and N. Islam, "Metabolic syndrome in type 2 diabetes: Comparison of WHO, modified ATP III and IDF criteria", Journal of Pakistan Medical Assocation, vol.62, no.6, pp. 569-574, 2012.

[30] A. O. Ogbera, "Prevalence and gender distribution of the metabolic syndrome", Diabetology and Metabolic Syndrome, vol. 2, no. 1, pp. 4, 2010

[31] R. Raman, A. Gupta, S. S. Pal, S. Ganesan, K. Venkatesh, V. Kulothungan, T. Sharma, "Prevalence of metabolic syndrome and its influence on microvascular complications in the Indian population with type 2 diabetes mellitus: Sankara Nethralaya Diabetic Retinopathy Epidemiology and Molecular Genetic Study (SN-DREAMS, report 14)", Diabetology and Metabolic Syndrome, vol. 2, no. 67, pp. 1-9, 2010.

[32] E. Dhanaraj, A. Bhansali, S. Jaggi, P. Dutra, S. Jain, P. Tiwari, P. Ramarao, "Prevalence and predictors of metabolic syndrome in non-obese Asian Indians with newly detected type 2 diabetes mellitus", Journal of Indian Medical Association vol. 106, no. 6, pp. 366-368, 370-372, 2008.

[33] S. M. Grundy, H. B., Jr. Brewer, J. I. Cleeman, S. C., Jr. Smith, and C. Lenfant, "Definition of metabolic syndrome: Report of the National Heart, Lung, and Blood Institute/American Heart Association conference on scientific issues related to Circulation", vol.109, no. 3, pp. 433-438, 2004.

[34] L. Fezeu, B. Balkau, A. P. Kengne, E. Sobngwi, and J. C. Mbanya, "Metabolic syndrome in a sub-Saharan African setting: central obesity may be the the key determinant", Atherosclerosis vol. 193, no. 1, pp. 70-76, 2007.

[35] E. S. Ford, W. H. Giles, and W. H. Dietz, "Prevalence of the metabolic syndrome among US adults: findings from the third National Health and Nutrition Examination Survey", Journal of the American Medical Association, vol. 287, no. 3, pp. 356379, 2002.

[36] G. T. Ko, C. S. Cockram, C. C. Chow, V. Yeung, W. B. Chan, W. Y. So, N. N. Chan, and J. C. Chan, "High prevalence of metabolic syndrome in Hong Kong Chinese--comparison of three diagnostic criteria", Diabetes Research and Clinical Practice vol. 69, no. 2, pp. 160-168, 2005.

[37] M. M. Fahlman, D. Boardley, C. P. Lambert, and M. G. Flynn, "Effects of endurance training and resistance training on plasma lipoprotein profiles in elderly women", Journal of
Gerontology series A Biological Sciences Medical-Science vol. 57, no.2, pp. B54-B60, 2002.

[38] W. E. Kraus, J. A. Houmard, B. D. Duscha, K. J. Knetzger, M. B. Wharton, J. S. McCartney, C. W. Bales, S. Henes, G. P. Samsa, J. D. Otvos, and K. R. Kulkarni, "Effects of the amount and intensity of exercise on plasma lipoproteins", New England Journal of Medicine, vol. 347, no. 19, pp. 1483-1492, 2002.

[39] L. Byberg, B. Zethelius, P. M. McKeigue, and H. O. Lithell, "Changes in physical activity are associated with changes in metabolic cardiovascular risk factors", Diabetologia, vol. 44, no. 12, pp. 2134-2139, 2001.

[40] P. J. Arciero, M. D. Vukovich, J. O. Holloszy, S. B. Racette, and W. M. Kohrt, "Comparison of short-term diet and exercise on insulin action in individuals with abnormal glucose tolerance" Journal of Applied Physiology vol. 86, no. 6, pp. 930-1935, 1999.

[41] M. L. Irwin, E. J. Mayer-Davis, C. L. Addy, R. R. Pate, J. L. Durstine, L. M. Stolarczyk, and B. E. Ainsworth, "Moderateintensity physical activity and fasting insulin levels in women: the Cross-Cultural Activity Participation Study", Journal of Diabetes Care, vol. 23, no. 2, pp. 449-454, 2000.

[42] F. B. Hu, M. F. Leitzmann, M. J. Stampfer, G. A. Colditz, W. C. Willett, and E. B. Rimm, "Physical activity and television watching in relation to risk for type 2 diabetes mellitus in men", Journal of Archives Internal Medicine, vol. 161, no. 12, pp. 1542-1548, 2001.

[43] E. S. Ford, H. G. Wayne, and H. M. Ali. "Increasing prevalence of the metabolic syndrome among US adults," Diabetes care, vol. 27, no. 10, pp. 2444-2449, 2004.

[44] R. R. Dalacorte, C. L. Reichert, and J. L. Vieira, "Metabolic syndrome and physical activity in southern Brazilian community-dwelling elders: a population based, crosssectional study", BioMed Central Public Health, vol.25, no. 9, pp. 1471-2458, 2009.

[45] C. E. Tudor-Locke, and A. M. Myers, "Challenges and opportunities for measuring physical activity in sedentary adults”, Sports Medicine, vol. 31, no.2, pp. 91-100, 2001.

[46] J. A. Heady, J. N. Morris, and P. A. Raffle, "Physique of London busmen; epidemiology of uniforms", Lancet, vol. 271, no. 6942 , pp.569-570, 1956.

[47] J. Ekezie, S. S. Adebisi, and B. Danborno, "The Effect of Marital Status and Self-Reported Physical Exercise on the Adiposity and Blood Pressure of the Igbos of Nigeria", Internet Journal of Medical Update, vol.4, no. 1, pp. 7-14, 2009. 